\title{
(Implementation of Strategic Plans on Oil aße Distributors: A Study on Selected Oil Companies in Kenya
}

\author{
Yussuf Dahir Awale $^{1 *}$, Gregory Namusonge ${ }^{2}$, Kule Julius Warren ${ }^{3}$ \\ ${ }^{1}$ EMBA, Department of Business Administration, Jomo Kenyatta University of Agriculture and Technology, Kigali, RWANDA \\ ${ }^{2}$ Professor, School of Entrepreneurship, Procurement and Management, Jomo Kenyatta University of Agriculture and Technology, Kigali, \\ RWANDA \\ ${ }^{3}$ Head of Department, Department of Management and Social Sciences, Jomo Kenyatta University of Agriculture and Technology, Kigali, \\ RWANDA
}

*E-mail for correspondence: yussufdahir@gmail.com

Received: May 04, 2016;

Accepted: July 20, 2016;

Published: Oct 13, 2016

Source of Support: Nil

No Conflict of Interest: Declared

\begin{abstract}
The essence of strategy is to attempt to relate the organization to the changes in the environment. For any organization, strategy helps in interrogating the long term plans and ensuring that there is harmony between the vision, mission, objectives, core values, activities and its environment. Strategy formulation and implementation are core management functions. The developed strategy may be good but if its implementation is poor the intended strategic objectives may not be achieved. To ensure survival and success, firms do not only need to formulate strategies that seek to constantly maintain a match between the organization and its environment but also must ensure appropriate execution of strategy at all levels. Success therefore calls for proactive approach to business. The study aimed at identifying the determinants of strategy implementation plans on oil distributors in Kenya. Specifically, the study attempted to achieve the following objectives: to determine the effect of organizational structure; organizational culture; leadership; resource allocation and to establish the effect of communication on implementation of strategic plans on oil distributors in Kenya. The study was based on resource-based theory; dynamic capability theory and knowledge-based view theory. The study adopted a survey design that had used cross-sectional survey approach to collect data. The population of the study comprised of 14 oil distributors in Kenya based in Nairobi County. The target respondents comprised of 64 business owners and 136 managers therefore comprising of a target population of 200 respondents. A sample size of 60 respondents was selected for the study. Primary data was collected through semi-structured questionnaires. Data was coded in SPSS and Excel software for analysis where the tables of frequencies, percentage, mean and standard deviation was extracted for presentation of data. Inferential statistics was done to establish the relationship between the implementation of strategic plans and the five independent variables. The outcome of the study was to establish whether organizational structure; organizational culture; leadership; resource allocation and corporate communication affect the implementation of strategic plans in the oil distributors sector in Nairobi County. The research recommends that for oil distributors to improve on the implementation of strategic plans they need to enhance of teamwork, accountability, transparency and communication.
\end{abstract}

Keywords: Strategy, Implementation, organizational structure, organizational culture and corporate communication

\section{INTRODUCTION}

Thompson and Strickland (1989) define strategy implementation plan as acting on what has to be done internally to put the chosen strategy into place and to actually achieve the targeted results. They further argue that strategy implementation is primarily an administrative task that involves figuring out workable approaches to executing the strategy and then, during the day-today operations, getting people to accomplish their jobs in a strategy-supportive and results achieving fashion. Strategy implementation is the action phase of the strategic management process. It is the strategic phase in which staying close to the customer, achieving competitive advantage, and pursuing excellence become realities (Pearce and Robinson, 2002).

There are four possible strategy implementation outcomes. These outcomes include success, trouble, failure, and roulette. Success occurs if a good strategy is 
appropriately implemented; trouble occurs if it's poorly implemented, failure happens if poor strategy is badly implemented, whereas roulette occurs if a poor strategy is appropriately implemented. Successful implementation of the strategy involves operationalization and institutionalization of strategy. Thompson and Strickland (1989) argue that indeed, good strategy and good implementation are the most trustworthy proof of good management.

\section{Statement of the Problem}

Whereas successful strategy formulation depends on business vision, market analysis and entrepreneurial management, successful implementation depends on working through, organizing, motivating, and creating a strong fit between strategy and how the organization does things. According to Day and Reibstein (2007), without understanding and commitment, strategy implementation efforts face major problems. Managers are prone to overlook implementation realities. David further indicated that only $10 \%$ of formulated strategies are successfully implemented. Alexander (1985) claimed that the overwhelming majority of the literature has been on the formulation side of the strategy and only lip service has been given to the other side of the coin, namely strategy implementation. Unfortunately, the drama still continues and the balanced view toward the importance of both sides, formulation and implementation, has not yet been achieved. Consequently, companies are still facing major difficulties during the implementation process (Ateng, 2007). Obare (2006), Koske (2003), Lumiti (2007), Ateng (2007) noted that good strategies have been written but very little has been achieved in their implementation. Although these studies give a good inside about strategy implementation, the studies do not explain what determinants influences strategy implementation. In addition, these studies were not based in oil distributors in Kenya. Given the pivotal role played by Kenya oil distributors in the economic performance of our country; this gap motivated the researcher to undertake this study.

\section{Significance of the Study}

The findings of this study would be useful to the management of oil distributors in Kenya as it will provide significant information on determinants of implementation of strategic plans. Therefore, the study would provide the basis for the management to formulate strategies to enable successful implementation of strategic plans. Indeed, this study would ultimately enable oil distributors in Kenya to effectively implement their strategies and leads to superior performance.

Policy makers in other organizations would equally benefit from the findings of this study. The results of the study would furnish them with knowledge on the determinants of implementation of strategic plans and therefore enhance the survival and success of firms. This knowledge if well harnessed would result in above average performance of a firm in an industry. Lastly, scholars would also find the results of this study useful. On one hand, the findings of the study would add to the existing body of knowledge in the field of strategic management. Further, the study would also act as a springing board for future research in implementation of strategy in other organizations and likewise in other related areas.

\section{LITERATURE REVIEW}

Structure expresses how organizations are administered. It describes lines of authority, data flow through the lines and specifies roles, procedures, governance mechanism and decision making processes. The business strategy will quite often than not determine the choice of an organization structure hence the assertion that "Structure follows strategy" (Paton \& McCalman, 2008).

Therefore there must be some congruence or a fit between the organization structure and the existing strategy in order to avoid unprecedented turbulence and waste of resources through conflict. Inconsistent organization structure must be re aligned, be practical and acceptable and must follow the business strategy in order to make it possible to achieve the goals. The researcher notes very clearly that organizational structure can help or hinder, support or block strategic change and that a good fit-forpurpose structure will enable changes, continuous or discontinuous, small or large, to be made effectively and efficiently (Johnson \& Scholes, 2003).

Culture dictates what groups of people pay attention to, guides how the world is perceived, how the self is experienced and how life itself is organized. In oil distributors in Kenya, the management philosophy quite often determines the business culture, which translates to the shared values, expectations, and norms that are established in a business over time. Each business has its own culture, just as each individual has his or her own personality and this business culture determines how things are done in the business, for example how problems are approached and priorities determined in the execution of the work (Wang, 2000).

Organization culture may reflect in various forms and norms adopted by the organization such as the physical infrastructure, routine behavior, language, ceremonies, gender equality, and equity payment. If the proposed strategic changes contradict cultural biases and tradition, it is inevitable that they will be difficult to embed in the organization. This culture communicates to people through symbols, values, physical settings, language and thereby supplements the rational management tool such as technology and structure. Therefore successful implementation of a strategy demands a compatible business culture (Sharma, 2007).

Leadership is the human factor that leads an institution towards realizing goals through voluntary co-operation of all the people in the business. A business often succeeds or fails because of the presence or absence of good 
leadership. The Chief Executive Officer (CEO) is instrumental in the creation of the Vision of the organization. The CEO's leadership and actual involvement is critical in the strategy development and implementation process and will determine the level of support and backing to the new strategy (Roney, 2004).

Leadership determines how subordinate carry out assignments and depends on an ability to acquire and use power from both positional and personal sources. Leadership is the entire process of translating strategy into results and is essential in engaging the hearts and minds of the people. Good and visionary leadership creates efficiency by moving decision making responsibility to the frontline and will facilitate the success of implementing strategy (Thompson et al., 2007).

In order to carry out the strategic plans, adequate resources are required. In this study, resources will include time, human capital, and budgetary allocations. Resources will be utilized in the delivery of goods and services, and to carry out the strategic plan on a continuous basis throughout the predetermined life cycle (Kumar et al, 2006). In order to implement the strategic plans well, adequate resources must be allocated such as necessary time, financial resources, skills and knowledge. For instance financial resources will be utilized to support communication, provide training and incentives to the human capital. Adequate time must be available in order to complete the implementation process (Wery \& Waco, 2004).

For the purpose of this study, the dependent variable is the implementation of strategical plans because they will indicate the total influence of the five independent variables. The measures of implementation of strategic plans were identified as followed: Efficiency measures: These measures are productivity and cost effectiveness measured as ratio of outputs per inputs. Examples of efficiency measures include turnaround time per application processed and number of students graduating to number of students enrolled. Outcomes measures: These measures are the end result of whether services meet proposed targets or standards and demonstrate impact and benefit of activities. Examples include the percent increase in internships and the application to enrolled yield rate. Quality measures: These measures gauge effectiveness of expectations and generally show improvement in accuracy, reliability, courtesy, competence, responsiveness, and compliance. Examples of quality measures include number of audits with no findings or within a range of accuracy. Project measures: These measures show progress against an initiative that has a terminus. The measure is usually stated as the percent complete.

\section{Research Methodology}

A descriptive survey design was adopted as research design. This method uses cross sectional survey approach. According to Mugenda and Mugenda (2003), descriptive survey is a method, which enables the researcher to summarize and organize data in an effective and meaningful way. Cooper and Schindler (2003) stress that descriptive survey method is concerned with finding out who, what, where, when and how much.

The target population consists of 14 oil distributors in Kenya based in Nairobi County due to its accessibility for the purpose of the study. The target respondents are comprised of the owners of the business and the managers in charge. The business owners are the 64 respondents while the managers in charge 136 respondents. In total, the target population comprised of 200 respondents. The study sampled the required population for study using the $30 \%$ principle for Mugenda and Mugenda (2003), therefore, the sample population of the study comprised of 60 respondents.

Both primary and secondary sources of data were used to obtain information for the study. Primary data were obtained through semi-structured questionnaires. After questionnaires had been received from the field, they were edited and prepared for keying in for processing. The questionnaires are then to be keyed in the computer using Excel and SPPS package. Data was analyzed using SPSS and Excel software from which summary tables were prepared. The next step is report writing where the research results are presented using simple descriptive statistics such as the mean, percentage ratios, and dispersions from which tables and bar graphs were derived.

The researcher conducted a multiple regression analysis so as to determine the relationship between the implementation of strategic plans and the five independent variables. The regression equation

$$
\begin{aligned}
& \left(\mathrm{Y}=\boldsymbol{\beta}_{0}+\boldsymbol{\beta}_{1} \mathrm{X}_{1}+\boldsymbol{\beta}_{2} \mathrm{X}_{2}+\boldsymbol{\beta}_{3} \mathrm{X}_{3}+\boldsymbol{\beta}_{4} \mathrm{X}_{4}+\boldsymbol{\beta}_{5} \mathrm{X}_{5}+\boldsymbol{\varepsilon}\right) \text { : } \\
& \qquad \begin{array}{l}
\mathrm{Y}=\text { Implementation of Strategic Plans, } \\
\mathrm{X}_{1}=\text { Organizational Structure } \\
\mathrm{X}_{2}=\text { Organizational Culture, } \\
\mathrm{X}_{3}=\text { Organizational Leadership } \\
\mathrm{X}_{4}=\text { Resource Allocation, } \\
\mathrm{X}_{5}=\text { Communication } \\
\varepsilon=\text { Statistical Error }
\end{array}
\end{aligned}
$$

\section{STUDY FINDINGS}

This part presents analysis and findings of the research. The objective of this study was to determine the factors that influence implementation of strategic plans in oil distributors in Kenya. Data collection instrument were questionnaires, which were sent to a sample of 229 respondents. However, 169 questionnaires were returned adequately filled in, making a response rate of $73.8 \%$. 


\section{Factors Influencing Implementation of Strategic Plans}

The study sought to establish factors influencing implementation of strategic plans on oil distributors in Kenya. The responses regarding to the statement that the organizations under study reporting relationship affected the implementation of strategic plans had mean of 3.60; organization structure clearly specifying the work to be done had a mean of 3.31 while key implementation tasks being sufficiently designed had a mean of 3.24. The respondents' responses on organizational structure supporting implementation of strategic plans had a mean of 2.93 and those who agreed to the statement that organizational structure is acceptable to employees had a mean of 2.92. This underscored the significance of reporting relationship being important in the implementation of strategic plans. The results also show that organization structure and sufficient definition of tasks to be implemented as important implementation of strategic plans.

Table 1: How organization structure influences implementation of strategic plans

\begin{tabular}{|l|c|c|}
\hline & Mean & STDEV \\
\hline $\begin{array}{l}\text { Organizational structure support to } \\
\text { implementation of strategic plans }\end{array}$ & 2.93 & 1.019 \\
\hline $\begin{array}{l}\text { Effect of reporting relationship on } \\
\text { implementation of strategic plans }\end{array}$ & 3.60 & 0.972 \\
\hline $\begin{array}{l}\text { Organization structure clearly } \\
\text { specifies the work to be done }\end{array}$ & 3.31 & 1.220 \\
\hline $\begin{array}{l}\text { Key implementation tasks are } \\
\text { sufficiently defined }\end{array}$ & 3.24 & 1.099 \\
\hline $\begin{array}{l}\text { Organizational structure is acceptable } \\
\text { to employees }\end{array}$ & 2.92 & 1.207 \\
\hline
\end{tabular}

\section{Institutional Procedures}

The study sought to establish whether institutional procedures are necessary or not?

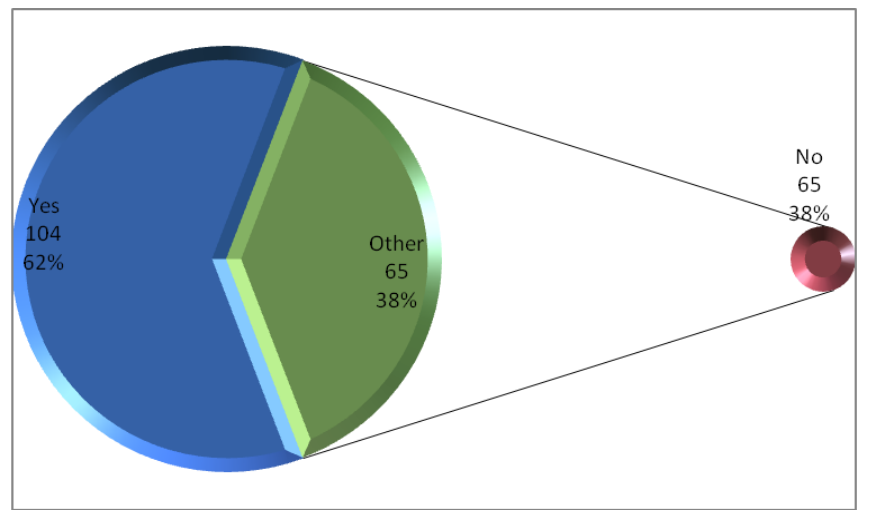

Figure 1: Whether Institutional Procedures are not necessary

From the findings in figure 4.2, 62 percent of the respondents agreed that institutional procedures are necessary while 38 percent of the respondents objected necessity of institutional procedures. These illustrate the necessity of internal procedures in the implementation of strategic plans in the enterprises.
The study sought to establish how organizational culture influence implementation of strategic plans.

Table 2: How Organizational Culture Influence Implementation Of Strategic Plans

\begin{tabular}{|l|c|c|}
\hline & Mean & STDEV \\
\hline $\begin{array}{l}\text { Organizational culture supports } \\
\text { implementation }\end{array}$ & 3.18 & 0.861 \\
\hline $\begin{array}{l}\text { Organizational culture should be } \\
\text { changed to be effective }\end{array}$ & 3.85 & 1.113 \\
\hline Information flow is free & 2.64 & 1.306 \\
\hline Organizational vision is widely shared & 3.21 & 1.063 \\
\hline
\end{tabular}

The respondents who agreed to the statement that Organizational culture should be changed in order to be effective had a mean of 3.85 followed by the respondents who agreed to the statement that vision is widely shared at a mean of 3.21, the respondents who supported the statement that organizational culture supports implementation had a mean of 3.18 and finally, minority of the respondents (with a mean of 2.64) agreed to the statement that Information flow is free. This draws attention to the fact that while the Organizational culture is shared among the employee, majority of the respondents feel that the organization culture should be changed which would in turn influence implementation of strategic plans positively.

The study sought to find out how leadership influences implementation of strategic plans.

Table 3: How leadership influences implementation of strategic plans.

\begin{tabular}{|l|c|c|}
\hline & Mean & STDEV \\
\hline $\begin{array}{l}\text { Top management support } \\
\text { implementation }\end{array}$ & 3.57 & .850 \\
\hline $\begin{array}{l}\text { Direction given by top management } \\
\text { is adequate }\end{array}$ & 2.92 & .966 \\
\hline $\begin{array}{l}\text { Formulators of strategic plans are not } \\
\text { active in } \\
\text { Implementation }\end{array}$ & 3.23 & .886 \\
\hline $\begin{array}{l}\text { Management teams are accessible and } \\
\text { open to Juniors }\end{array}$ & 2.68 & 1.026 \\
\hline $\begin{array}{l}\text { Sub-ordinates willing to strive to } \\
\text { achieve leaders aim }\end{array}$ & 3.40 & 1.070 \\
\hline
\end{tabular}

From the findings, the statement that top management support implementation had a mean of 3.57 followed the statement that subordinates are willing to strive to achieve leaders aim at a mean of 3.40; formulators of strategic plans not being active in implementation had a mean of 3.23, direction is given by top management being adequate had a mean of 2.92 and management teams being accessible and open to juniors had a mean of 2.68.

The study sought to investigate whether leadership style inspires effective implementation of strategies at the enterprises under study. 


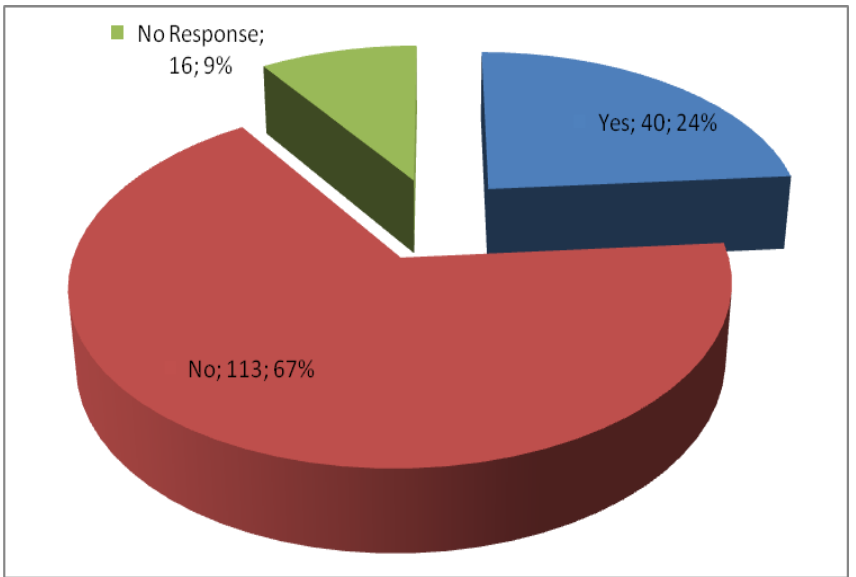

Figure 2: Leadership Style Inspires Effective Implementation of Strategy

From the findings, 24 percent of the respondents agreed that leadership style inspires effective implementation while 67 percent of the respondents did not agree. It can be deduced that leadership style does not inspire implementation of strategic plans.

Table 4: How Resources Allocation influenced implementation of strategic plans

\begin{tabular}{|l|c|c|}
\hline & Mean & STDV \\
\hline Tasks and activities are adequately funded & 1.70 & .808 \\
\hline Different activities compete for same resources & 3.87 & 1.078 \\
\hline Implementation delayed by scarcity of resources & 4.01 & 1.208 \\
\hline There is idle capacity due to poor flow of resources & 3.76 & 1.280 \\
\hline
\end{tabular}

The study investigated how resource allocation influenced implementation of strategic plans. The implementation being delayed by scarcity of resources had a mean of 4.01; different activities competing for same resources had a mean of 3.87. The responses to the statements that there is idle capacity due to poor flow of resources and tasks and activities being adequately funded had means of 3.76 and 1.70 respectively. This shows that scarcity of resources with different activities competing for same resources has overtime hindered implementation of strategic plans. The findings also show that while tasks and activities are adequately funded, idle capacity owing to poor flow of resources affect implementation of strategic plans.

The study sought to establish how communication influenced implementation of strategic plans on oil distributors in Kenya.

Table 5: How Communication Influenced Implementation of Strategic Plans

\begin{tabular}{|l|c|c|}
\hline & Mean & STDEV \\
\hline Vision was adequately communicated & 3.76 & 1.137 \\
\hline $\begin{array}{l}\text { Organizational goals not sufficiently } \\
\text { explained }\end{array}$ & 2.84 & 1.125 \\
\hline $\begin{array}{l}\text { Problems escalated by junior to } \\
\text { management were not timely } \\
\text { communicated }\end{array}$ & 3.71 & .834 \\
\hline No open channels of communication & 2.86 & 1.141 \\
\hline
\end{tabular}

From the results in Table 4.9 above the responses to the statement that vision are adequately communicated had a mean of 3.76, the statements that problems escalated by junior to management were not timely communicated, there is no open channel of communication and organizational goals not being sufficiently explained had means of 3.71, 2.86 and 2.86 respectively. His illustrated the fact that while vision is adequately communicated, more needs to be done in communicating problems escalated by junior to management.

The researcher further investigated whether clear communication of changes in the responsibility of employees influenced implementation of strategic plans.

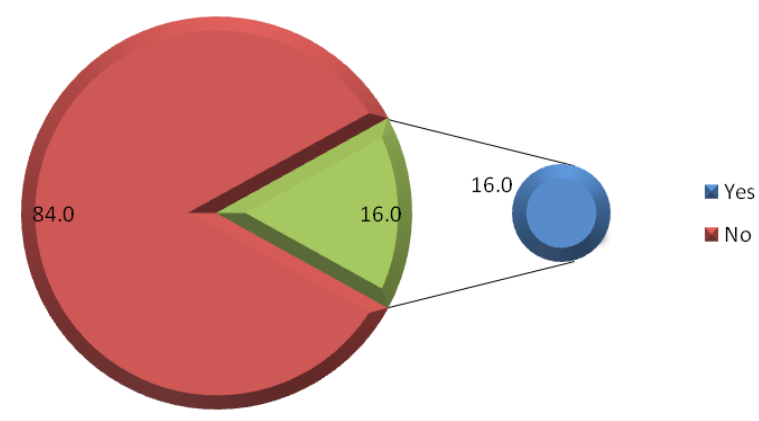

Figure 3: Clear Communication of Changes in Responsibility of Employees

Eighty-four (84.0) percent of the respondents said that clear communication of changes in the responsibility of employees does not influence implementation of strategic plans while 16.0 percent had a differing opinion. This underscores the fact that lack of clear communication of changes in responsibility of employees has overtime hindered the implementation of strategic plans.

The study sought to find out how strategic plans were implemented at the organization under study.

Table 6: Implementation of Strategic Plans

\begin{tabular}{|l|c|c|}
\hline $\begin{array}{l}\text { Organization structure has been aligned } \\
\text { to strategic plan }\end{array}$ & Mean & STDEV \\
\hline Enhanced communication & 3.51 & .946 \\
\hline Enhanced teamwork & 3.22 & .930 \\
\hline Reforms are being undertaken & 3.38 & .830 \\
\hline $\begin{array}{l}\text { Enhanced accountability and } \\
\text { transparency }\end{array}$ & 3.75 & .808 \\
\hline Friendly service delivery & 3.37 & .891 \\
\hline & 3.77 & .880 \\
\hline
\end{tabular}

The respondents who supported the statement that there is friendly service delivery had a mean of 3.77. The respondents who supported to statements that reforms are being undertaken, organizational structure has been aligned to strategic plan, there was enhanced teamwork, there was enhanced accountability and transparency and that there was enhanced communication had means of $3.75,3.51,3.38,3.37$ and 3.22 respectively. This illustrates 
that strategic plans implementation has been facilitated by friendly service delivery, reforms being undertaken, organization structure being aligned to strategic plan, teamwork and enhanced accountability and transparency.

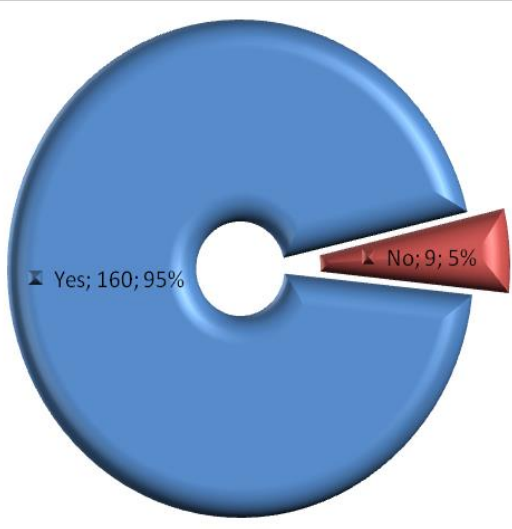

Figure 4: Attribution of Successful Implementation of Strategic Plans to Revenue Collection.

The researcher sought to establish whether successful implementation of strategic plans be attributed to revenue collection. From the results in figure 6 above, 95 percent of the respondents agreed that successful implementation of strategic plans can be attributed to revenue collection while 5 percent of the respondents had a different opinion account of the same. These illustrate that successful implementation of strategic plans was attributed to revenue collection.

\section{Regression Analysis}

Table 7: Coefficient of Determination (R2)

\begin{tabular}{|c|c|c|c|c|}
\hline Model & âRâ & R Square & $\begin{array}{c}\text { Adjusted } \\
\text { R Square }\end{array}$ & $\begin{array}{c}\text { Std. Error of } \\
\text { the Estimate }\end{array}$ \\
\hline 1 & $.742(\mathrm{a})$ & .551 & .546 & .46316 \\
\hline
\end{tabular}

Predictors: (Constant), organizational structure, organizational culture, organizational leadership, resource allocation, and communication

Coefficient of determination explains the extent to which changes in the dependent variable be explained by the change in the independent variables or the percentage of variation in the dependent variable (implementation of strategic plans) that is explained by all the five independent variables (organizational structure, organizational culture, organizational leadership, resource allocation, and communication).

The five independent variables that were studied, explain only $55.1 \%$ of the implementation of strategic plans as represented by the $\mathrm{R} 2$. Therefore, this means the five independent variables only contribute about $55.1 \%$ to the implementation of strategic plans while other factors not studied in this research contributes $44.9 \%$ of the implementation of strategic plans.

Therefore, further research should be conducted to investigate the other factors $(44.9 \%)$ that contribute to the implementation of strategic plans.

Table 8: ANOVA

\begin{tabular}{|c|l|c|c|c|c|c|}
\hline Model & & $\begin{array}{c}\text { Sum of } \\
\text { Squares }\end{array}$ & df & $\begin{array}{c}\text { Mean } \\
\text { Square }\end{array}$ & F & Sig. \\
\hline 1 & Regression & 6.347 & 2 & 3.173 & 1.899 & $.0151(\mathrm{a})$ \\
\hline & Residual & 621.530 & 372 & 1.671 & & \\
\hline & Total & 627.877 & 374 & & & \\
\hline
\end{tabular}

The significance value is 0.0151 which is less that 0.05 thus the model is not statistically significance in predicting how organizational structure, organizational culture, organizational leadership, resource allocation, and communication affect the implementation of strategic plans.

Table 9: Multiple Regression Analysis

\begin{tabular}{|c|c|c|c|c|c|c|}
\hline Model & & \multicolumn{2}{|c|}{ Unstandardized Coefficients } & Standardized Coefficients & $\mathrm{T}$ & Sig. \\
\hline & & B & Std. Error & Beta & & \\
\hline 1 & (Constant) & 1.334 & .311 & & 4.285 & .000 \\
\hline & Organizational structure & 0.144 & .164 & -.193 & -.876 & .00387 \\
\hline & Organizational culture & 0.0196 & 0.0481 & 0.0327 & 0.4069 & 0.016 \\
\hline & Organizational leadership & 0.1981 & 0.0714 & 0.2325 & 2.7736 & 0.0062 \\
\hline & Resource allocation & 0.0288 & 0.0501 & 0.0484 & 0.5759 & 0.02655 \\
\hline & Communication & 0.140 & 0.020 & 0.013 & 0.714 & 0.0374 \\
\hline
\end{tabular}

Dependent Variable: Implementation of strategic plans

The researcher conducted a multiple regression analysis so as to determine the relationship between the implementation of strategic plans and the five variables. The regression equation

$\left(Y=\beta_{0}+\beta_{1} X_{1}+\beta_{2} X_{2}+\beta_{3} X_{3}+\beta_{4} X_{4}+\beta_{5} X_{5}+\varepsilon\right)$ will be:

$Y=1.334+0.144 X_{1}+0.0196 X_{2}+0.1981 X_{3}+0.0288 X_{4}+$ $0.140 X_{5}$

Whereby

$\mathrm{Y}=$ Implementation of Strategic Plans
$\mathrm{X}_{1}=$ Organizational Structure; $\mathrm{X}_{2}=$ Organizational Culture; $X_{3}=$ Organizational Leadership; $X_{4}=$ Resource Allocation, and $X_{5}=$ Communication

According to the regression equation established, taking all factors (organizational structure, organizational culture, organizational leadership, resource allocation and communication) constant at zero, the implementation of strategic plans will be 1.334 . The data findings analyzed also shows that taking all other independent variables at zero, a unit increase in organizational structure will lead to a 0.144 increase in implementation of strategic plans. A 
unit increase in organizational culture will lead to a 0.0196 increase in implementation of strategic plans; a unit increase in organizational leadership will lead to a 0.1981increase in implementation of strategic plans, a unit increase in resource allocation will lead to a 0.0288 increase in implementation of strategic plans while a unit increase in communication will lead to a 0.140 increase in implementation of strategic plans. This infers that organizational leadership contributed more to the implementation of strategic plans followed by organizational structure.

\section{SUMMARY OF FINDINGS}

According to the study, findings analyzed in the study established that on the demographic characterization of respondents, majorities (56.2 percent) were male, and 43.8 percent were female. The data findings further showed that majority of the respondents (58.0 percent) were aged below 30 years followed by those in age brackets 30 to 40 years, and the rest aged above 40 years.

With regards to factors influencing implementation of strategic plans, the majority of the respondents (with a mean of 3.60) agreed that reporting relationship greatly affected implementation of strategic plans and very few respondents (with a mean of 2.92) said that organizational structure is acceptable to employees. On the necessity of institutional procedures 62 percent of the respondents agreed that institutional procedures are necessary while 38 percent of the respondents objected necessity of institutional procedures.

The findings on the influence organizational culture on implementation of strategic plans indicated that majority of the respondents (with a mean of 3.85) said that organizational culture should be changed in order to be effective. The respondents who agreed to the statement that organizational vision is widely shared at a mean of 3.21 followed them. The respondents who supported the statement that organizational culture supports implementation had a mean of 3.18 and finally few respondents (with a mean of 2.64) were in support of free flow of information at the organizational under study.

Results on influences of leadership on implementation of strategic plans revealed that most of respondents, with a mean of 3.57, are of the opinion that top management support implementation followed by the respondents who agreed that subordinates are willing to strive to achieve leaders aim at a mean of 3.40.while minority of the respondents (with a mean of 2.68) were in support of the view that management teams are accessible and open to juniors. The view that leadership style inspires effective implementation of strategies lacks support as denoted by 67 percent of the respondents who did not agree with the view. Only 24 percent of the respondents agreed that leadership style inspires effective implementation.

On the influence of resource allocation on the implementation of strategic plans on oil distributors in
Kenya, most of the respondents supported the statement that implementation was delayed by the scarcity of resources at a mean of 4.01. On the other hand, the presence of idle capacity due to poor flow of resources had little support at a mean of 1.70. Results on the influenced of communication on the implementation of strategic plans in Kenya oil distributors indicated that most of the respondents (at a mean of 3.76) agreed that vision was adequately communicated while few (with a mean of 2.86) said that organization goals were not sufficiently explained. With regard to about whether clear communication of changes in the responsibility of employees influenced implementation of strategic plans majority (84.0 percent) disagreed.

Finally, friendliness services delivered was widely supported at a mean of 3.77. The undertaking of reforms, alignment of organizational structure to strategic plan, enhancement of teamwork, enhancement of accountability and transparency and enhancement of communication had means of $3.75,3.51,3.38,3.37$ and 3.22 respectively.

\section{REFERENCES}

Alexander, L. (2001). Strategy implementation: nature of the problem. International Review of Strategic Management, Vol. 2, No.1, Pp.73-91.

Ateng, F. (2007). Challenges of Strategy Implementation at the Ministry of Finance in Kenya. Unpublished MBA Dissertation: University of Nairobi.

Day, G. and Reibstein, D. (2007) Dynamic Competitive Strategy. New Jersey: John Wiley \& Sons Inc.

Johnson, G., and Scholes, K. (2003). Exploring Corporate Strategy (6 ${ }^{\text {th }}$ ed.). New Delhi: Prentice Hall of India Private Ltd.

Koske, F.K. (2003). Strategy Implementation and Its Challenges in Public Corporations: The Case of Telkom Kenya Ltd (Unpublished MBA Dissertation)

Kumar, R., Markeset, T. and Kumar, U. (2006).Implementation and Execution of Industrial Service Strategy. Quality in Maintenance Engineering, Vol. 12, No. 2, Pp. 105-117

Lumiti, A. P. (2007). Strategic Implementation of CDF. Unpublished MBA Thesis: Kenyatta University.

Mugenda M. O. and Mugenda G.A. (2003): Research Methods: Qualitative and Quantitative Approaches, Revised, Acts Press.

Obare, J.G. (2006). Implementation of Strategic Plans in the Public Sector: A Case Study of Directorate of Personnel Management in the Government of Kenya. Unpublished MBA Dissertation: University of Nairobi.

Paton, A. and McCalman, J. (2008). Change Management a Guide to Effective Implementation ( $\left.2^{\text {nd }} e d.\right)$. London: Sage Publications Ltd.

Pearce, (11) J. A. and Robinson, (Jr.) R. B. (2001).Strategic Management; Formulation, Implementation and Control (4th ed.). USA: Richard D. Irwin.

Roney, C. W. (2004). Strategy Management Methodology. USA: Praeger Publishers.

Sharma, R. R. (2007). Change Management: Concepts and Applications. New Delhi: Tata McGraw-Hill. 
Thompson (Jr.) A. A. and Strickland (111) A. J. (1989).Strategy formulation and implementation: Task of the General Manager (4th Ed.). USA: Richard D. Irwin.

Thompson, A., Strickland, A. and Gamble, J. E. (2007). Crafting and Executing Strategy (15 ${ }^{\text {th }}$ Ed.). New York: McGraw- Hill.
Wang, Y. (2000). Strategy Implementation: Seminar Study in Strategy and Internal Business. Unpublished Report, Helsinki University of Technology, Institute of Strategy and International Business, Helsinki, Finland.

Wery, R., \& Waco, M. (2004). Why good strategies fail. Handbook of Business Strategy, Vol. 5, No.1, Pp.153-7.

$--0-$

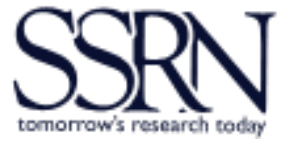

\section{SoCIAL ScIENCE RESEARCH NETWORK \\ 2171 Monroe Avenue, Suite 203, Rochester, NY 14618, USA http://www.ssrn.com/en/}

AJTP Link: http://www.ssrn.com/link/American-Journal-Trade-Policy.html 